Canadian

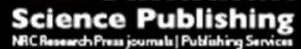

Canadian Journal of Physiology and Pharmacology Revue canadienne de physiologie et pharmacologie

\title{
Acute effects of nandrolone decanoate on cardiodynamic parameters in isolated rat heart
}

\begin{tabular}{|c|c|}
\hline Journal: & Canadian Journal of Physiology and Pharmacology \\
\hline Manuscript ID & cjpp-2015-0571.R1 \\
\hline Manuscript Type: & Article \\
\hline Date Submitted by the Author: & 08-Feb-2016 \\
\hline Complete List of Authors: & $\begin{array}{l}\text { Nikolic, Tamara; Faculty of Medical Sciences, University of Kragujevac, } \\
\text { Svetozara Markovica 69, } 34000 \text { Kragujevac, Serbia, Department of } \\
\text { Pharmacy } \\
\text { Zivkovic, Vladimir; Faculty of Medical Sciences, University of Kragujevac, } \\
\text { Department of Physiology } \\
\text { Srejovic, Ivan; Faculty of Medical Sciences, University of Kragujevac, } \\
\text { Svetozara Markovica 69, 34000, Kragujevac, Serbia, Department of } \\
\text { Physiology, } \\
\text { Radovanovic, Dragan; Faculty of Sport and Physical Education, Department } \\
\text { of Physiology } \\
\text { Jeremic, Nevena; Faculty of Medicine, Department of Pharmacy } \\
\text { Jevdjevic, Maja; College of Health Studies in Cuprija, Bulevar Vojske bb, } \\
\text { 35230 Cuprija, Serbia } \\
\text { Djuric, Dragan; School of Medicine University of Belgrade, Institute of } \\
\text { Medical Physiology } \\
\text { Jakovljevic, Vladimir; Faculty of Medicine University of Kragujevac }\end{array}$ \\
\hline Keyword: & nandrolone decanoate, cardiodynamics, coronary flow, isolated rat heart \\
\hline
\end{tabular}

\section{SCHOLARONE"}

Manuscripts 


\section{Acute effects of nandrolone decanoate on cardiodynamic parameters in isolated rat heart}

Tamara R. Nikolic ${ }^{1}$, Vladimir I. Zivkovic ${ }^{2}$, Ivan M. Srejovic ${ }^{2}$, Dragan S. Radovanovic ${ }^{3}$, Nevena S. Jeremic ${ }^{1}$, Maja D. Jevdjevic ${ }^{4}$, Dragan M. Djuric ${ }^{5}$, Vladimir Lj. Jakovljevic ${ }^{2}$

${ }^{I}$ Department of Pharmacy, Faculty of Medical Sciences, University of Kragujevac, Svetozara Markovica 69, 34000 Kragujevac, Serbia

${ }^{2}$ Department of Physiology, Faculty of Medical Sciences, University of Kragujevac, Zmaj Jovina 30, 34000, Kragujevac, Serbia

${ }^{3}$ Department of Physiology, Faculty of Sport and Physical Education, University of Nis, Carnojeviceva 10A, 18000 Nis, Serbia

${ }^{4}$ College of Health Studies in Cuprija, Bulevar Vojske bb, 35230 Cuprija, Serbia

5Institute of Medical Physiology "Richard Burian", School of Medicine, University of Belgrade, Visegradska 26, 11000 Belgrade, Serbia

\section{Correspodence to:}

Vladimir Jakovljevic, Department of Physiology, Faculty of Medical Sciences, University of Kragujevac, Svetozara Markovica 69, 34000 Kragujevac, Serbia

Telephone: 381-34-342-944, fax: 381-34-306-800 ext 112, e-mail: tamara.nikolic@medf.kg.ac.rs

\section{Abbreviations}

AAS - anabolic androgenic steroids; LV - left ventricule; RV - right ventricule; ND nandrolone decanoate; HR - heart rate; CPP - coronary perfusion pressure; CF - coronary flow SEM - standard error mean; SD - standard deviation; 


\begin{abstract}
Despite worldwide use of anabolic steroids in last decades, there are still contradictory informations about their acute influence on myocardium. The aim of this study was to examine the acute effects of nandrolone decanoate (ND) on cardiodynamics and coronary flow in isolated rat heart. The hearts of male Wistar albino rats $(n=48,12$ per group, age 8 weeks, body mass 180-200 g) were excised and perfused according to Langendorff technique at gradually increased coronary perfusion pressures $\left(40-120 \mathrm{cmH}_{2} \mathrm{O}\right)$. After control sets of experiments, the hearts were perfused with ND in dose of $1 \mu \mathrm{M}, 10 \mu \mathrm{M}$ and $100 \mu \mathrm{M}$, successively. Using sensor placed in the left ventricle, we registered: maximum and minimum rate of pressure development in the left ventricle (dp/dt max and dp/dt min), systolic and diastolic left ventricular pressure (SLVP and DLVP) and heart rate (HR). Coronary flow (CF) was measured flowmetrically. The results clearly show the depression in cardiac function caused by higher doses of ND. The highest concentration of ND $(100 \mu \mathrm{M})$ induced most deleterious impact on the myocardial function and perfusion of the heart (coronary circulation), which could be of clinical significance.
\end{abstract}

Key words: nandrolone decanoate, cardiodynamics, coronary flow, isolated rat heart 


\section{Introduction}

Anabolic androgenic steroids (AAS) are synthetic compounds, made up of testosterone and its derivatives. When these AAS act via androgen receptor, they produce nearly similar anabolic and androgenic effects. Despite some therapeutic use of AASs, there is also wide abuse among athletes especially bodybuilders in order to improve their performances and to increase muscle growth and lean body mass, taking into account the significant anabolic effects of these drugs (Bird et al. 2015).

AAS have attracted the attention of health researchers because some athletes have been using them without prescription and at supraphysiological doses, with the purpose of increasing muscle mass or to improve physical performance (Momaya et al. 2015; Nieschlag and Vorona 2015; Piacentino et al. 2015). The prolonged misuse and abuse of AASs can determine several adverse effects, some of which may be even fatal especially on the cardiovascular system because they may increase the risk of sudden cardiac death (SCD), myocardial infarction, altered serum lipoproteins, and cardiac hypertrophy (Frati et al. 2015). The mechanisms responsible for the negative effect of AS on cardiovascular health are poorly understood, especially in humans (Angell et al 2012).

The anabolic androgenic steroid 19- nortestosterone, also called nandrolone, was first synthesised by Birch in 1950 (Le Bizec et al. 1999). Studies have demonstrated that treatment with nandrolone decanoate increases lean body mass and body weight in wasting or cachexia associated with HIV infection (Batterham and Garsia 2001; Gold et al. 1996; Sattler et al. 1999; Strawford et al. 1999) chronic obstructive pulmonary disease (Creutzberg et al. 2003; Schols et al. 1995), renal failure (Johansen et al. 1999), and long-term use of glucocorticosteroids (Crawford et al. 2003). The use of nandrolone by athletes became popular in the late 1950s. 
Athletes use nandrolone in an oral or injectable form to increase muscle strength and improve performance. As a result of the potential performance enhancing benefits and potential health risks associated with anabolic steroid use, the International Olympic Committee (IOC) prohibited the use of nandrolone in sport in 1976 (Bowers 2002; Kohler and Lambert 2002; Ryan 1981).

Today, little is known about impact of ND on cardiovascular system, especially about its direct effects on heart. Previous studies reported that these substances (AAS) exert primarily anabolic and growth-promoting effects in cardiac tissue (Chaves et al. 2013; Do Carmo et al. 2011; Egginton 1987; Isaacs et al. 2013; Racca et al. 2012; Riezzo et al. 2014). Brasil et al described that ND induces cardiac and renal remodeling in female rats but without modification in physiological parameters (Brasil et al. 2015), and also results of other study showed that chronically administered ND is able to disrupt the cellular redox balance, leading to an oxidative stress state in heart (Frankenfeld et al. 2014). On the other hand, the use of AAS is frequently associated with exercise and chronic administration and a lot of studies, in animal models, have attempted to find the relationship between chronic AAS administration with exercise and cardiovascular function (Georgieva and Boyadjiev 2004; Phillis et al. 2007; Pozzi et al. 2013).

In that sense, the aim of this study was to examine the acute effects of nandrolone decanoate (ND) on cardiodynamics and coronary flow in isolated rat heart.

\section{Materials and methods}

\section{Experimental animals}

Male Wistar rats were obtained from Military Medical Academy, Belgrade, Serbia. Rats had free access to water and food pellets and were kept on $12 \mathrm{~h} / 12 \mathrm{~h}$ light/dark cycle. In the experimental work were respected the provisions prescribed acts (EU Directive for the Protection 
of Vertebrate Animals used for Experimental and other Scientific Purposes 86/609/EEC) and the principles of ethics. The experimental protocol was approved by the Faculty of Medical Sciences Ethics Committee for the welfare of experimental animals, University of Kragujevac, Kragujevac, Serbia.

\section{Isolated rat heart preparation}

After short ketamine/xylazine narcosis, emergency thoracotomy was performed, and hearts of male Wistar albino rats ( $n=48,4$ groups, 12 per group, age 8 weeks, body mass 180 $200 \mathrm{~g}$ ) were attached to Langendorff apparatus via aortic cannula. The hearts were retrogradely perfused according to the Langendorff technique at gradually increased with perfusion pressure $\left(40 \mathrm{cmH}_{2} \mathrm{O}-120 \mathrm{cmH}_{2} \mathrm{O}\right)$. The hearts were perfused with Krebs-Henseleit solution, which were composed of: $\mathrm{NaCl} 118 \mathrm{mM}, \mathrm{KCl} 4.7 \mathrm{mM}, \mathrm{CaCl}_{2}$ × $2 \mathrm{H}_{2} \mathrm{O} 2.5 \mathrm{mM}, \mathrm{MgSO}_{4} \times 7 \mathrm{H}_{2} \mathrm{O} 1.7 \mathrm{mM}$, $\mathrm{NaHCO}_{3} 25 \mathrm{mM}, \mathrm{KH}_{2} \mathrm{PO}_{4} 1.2 \mathrm{mM}$, glucose $5.5 \mathrm{mM}$, equilibrated with $95 \% \mathrm{O}_{2} / 5 \% \mathrm{CO}_{2}$ and warmed to $37^{\circ} \mathrm{C}(\mathrm{pH} 7.4)$.

Immediately after the establishment of automatic operation, a latex balloon was inserted into the left chamber, through the incision of the left atrium and destroyed mitral valve. The balloon (large enough that pressure was not generated over the LV volume used in experiment) was filled with bubble-free saline and connected to a pressure sensor (transducer BS4 73-0184, Experimentria Ltd, Hungary) for continuous recording of the parameters of myocardial function.

Physiological assay and experimental protocol

After heart perfusion commenced, a 30 min period was allowed for stabilization of the heart. After an equilibration period $\left(70 \mathrm{cmH}_{2} \mathrm{O}\right), \mathrm{CPP}$ was lowered to $60 \mathrm{cmH}_{2} \mathrm{O}$ and then 
gradually increased to $80 \mathrm{cmH}_{2} \mathrm{O}, 100 \mathrm{cmH}_{2} \mathrm{O}$, and $120 \mathrm{cmH}_{2} \mathrm{O}$, and finally lower to $40 \mathrm{cmH}_{2} \mathrm{O}$. After setting up the control experimental protocol (Krebs-Henseleit physiological solution [control group]), the hearts of the first group were perfused with $1 \mu \mathrm{M}$, the second group with 10 $\mu \mathrm{M}$ and the third group with $100 \mu \mathrm{M}$ of ND.

The test period started immediately after the control experiments to avoid time-dependent adverse effects. The flow was considered to be stable at each value of perfusion pressure, when three repeated values of coronary flow (CF) were the same. CF was measured flowmetrically. Using sensor placed in the left ventricle, we registered the following parameters of myocardial function which were continuously recorded in the control and experimental groups:

a) maximum rate of left ventricular pressure development (dp/dt max);

b) minimum rate of left ventricular pressure development ( $\mathrm{dp} / \mathrm{dt} \mathrm{min})$;

c) systolic left ventricular pressure (SLVP);

d) diastolic left ventricular pressure (DLVP);

e) heart rate (HR) and

f) coronary flow (CF).

Drugs

Nandrolone decanoate $\left(\mathrm{DEKA}^{\circledR}, 300 \mathrm{mg} / 10 \mathrm{ml}\right)$ was purchased from Genox Laboratory, made in EU.

\section{Statistical analysis}

Statistical analysis of experimental data included the following basic descriptive statistics: the mean value $(\overline{\mathrm{x}})$ standard deviation $(\mathrm{SD})$ and standard error mean (SEM). For testing the 
normality of distribution parameters, the Kolmogorov-Smirnov test was used. To test the statistical significance of the results and to confirm the hypothesis, the following statistical tests were used: Student's t-test (parametric test), for dependent and independent variables. A database analysis of the results was performed using software package SPSS 20th (SPSS Inc. Chicago, IL, $U S A) . P<0.05$ was considered statistically significant.

\section{Results}

$\mathrm{dp} / \mathrm{dt} \max$

While concentrations of $100 \mu \mathrm{M}$ did not significantly affect dp/dt max over the entire CPP range (Fig. 1C), concentration of $1 \mu \mathrm{M}$ and $10 \mu \mathrm{M}$ induced a significantly decreases in this parameter at $\mathrm{CPP} 100 \mathrm{cmH}_{2} \mathrm{O}$ and $120 \mathrm{cmH}_{2} \mathrm{O}$ (Figs. 1A and 1B).

$\mathrm{dp} / \mathrm{dt} \min$

$\mathrm{dp} / \mathrm{dt}$ min was the most significantly decreased by: $10 \mu \mathrm{M}$ at $\mathrm{CPP} 80 \mathrm{cmH}_{2} \mathrm{O}, 100 \mathrm{cmH}_{2} \mathrm{O}$ and $120 \mathrm{cmH}_{2} \mathrm{O}$ (Fig. 2B), and dp/dt min was decreased by $1 \mu \mathrm{M} \mathrm{ND}$ at CPP $80 \mathrm{cmH}_{2} \mathrm{O}$ and by 100 $\mu \mathrm{M}$ ND at CPP $120 \mathrm{cmH}_{2} \mathrm{O}$ (Figs. 2A and 2C).

SLVP

Compared with control conditions, $1 \mu \mathrm{M}$ ND decreased SLVP at CPP $80 \mathrm{cmH}_{2} \mathrm{O}$ (Fig. 3A). Concentration of $10 \mu \mathrm{M}$ ND decreased SLVP at CPP $100 \mathrm{cmH}_{2} \mathrm{O}$ and $120 \mathrm{cmH}_{2} \mathrm{O}$ (Fig. 3B), but the higher dose of ND $(100 \mu \mathrm{M})$ induced more significant decrease of this parameter at CPP $120 \mathrm{cmH}_{2} \mathrm{O}$ and $80 \mathrm{cmH}_{2} \mathrm{O}$ (Fig. 3C). 


\section{$D L V P$}

Administration of ND in each tested concentration $(1 \mu \mathrm{M}, 10 \mu \mathrm{M}, 100 \mu \mathrm{M})$ did not significantly affect this parameter over the entire CPP range (Figs. 4A, 4B, 4C).

Heart rate $(H R)$

Compared with control conditions, only $1 \mu \mathrm{M}$ ND did not induce significant changes in HR (Fig. 5A). Both higher concentrations of ND $(10 \mu \mathrm{M}$ and $100 \mu \mathrm{M})$ induced significant decrease of $\mathrm{HR}$ at all $\mathrm{CPP}$, except $40 \mathrm{cmH}_{2} \mathrm{O}$, but changes induced by $100 \mu \mathrm{M}$ ND were more significant (Figs. 5B, 5C).

Coronary flow (CF)

While $1 \mu \mathrm{M}$ ND did not affect CF over the entire CPP range (Fig. 6A), ND in concentration of $10 \mu \mathrm{M}$ induced significant decrease at CPP $60 \mathrm{cmH}_{2} \mathrm{O}, 100 \mathrm{cmH}_{2} \mathrm{O}$ and 120 $\mathrm{cmH}_{2} \mathrm{O}$ (Fig. 6B). Concentration of $100 \mu \mathrm{M}$ ND induced more significant decrease at $\mathrm{CF}$ at CPP value $80 \mathrm{cmH}_{2} \mathrm{O}$ and especially at $\mathrm{CPP} 100 \mathrm{cmH}_{2} \mathrm{O}$ and $120 \mathrm{cmH}_{2} \mathrm{O}$ (Fig. 6C).

\section{Discussion}

The present study aimed to examine the effects of acute administration $(1 \mu \mathrm{M}, 10 \mu \mathrm{M}$, $100 \mu \mathrm{M})$ of ND $\left(\mathrm{DEKA}^{\circledR}\right)$ on cardiodynamic parameters and coronary autoregulation in isolated rat hearts. The main hypothesis of the present investigation was that lower doses of ND may have lower impact on isolated rat hearts than higher doses of ND. In this experiment, an artificial blood substitute (Krebs-Henseleit solution) was used to closely mimic the physiological state so 
we could exclude the influence of ND on platelets and examine its direct effect on myocardium (Zivkovic et al. 2012; 2013).

Cardiac contractility was estimated by maximum and minimum rate of LV pressure development (dp/dt max and $\mathrm{dp} / \mathrm{dt} \min$ ) who are indirect indicators of inotropic and lusitropic properties of the heart. In general, our result indicated that acutely administered ND caused decrease of both contractility forces of the myocardium at the highest CPP (Figs 3A-C).

There are lack of data reffering to a direct and acute effect of AAS on the cardiac muscle, especially ND, as one of the most commonly abused. Prevous data suggested that a single dose of ND $(20 \mathrm{mg} / \mathrm{kg})$ can cause any effect on cardiac muscle and concluded that ND exhibits cardiotrophic action especially towards the generation of NADPH which is involved in ROS hiperproduction (Tylicki et al. 2007). Nevertheless, results of our previous research clearly showed that acute administration of ND (in dose of 1-100 $\mu \mathrm{M}$ ) is not sufficient for significant modification of ROS synthesis in the rat heart (Jevdjevic et al. 2015). Based on these data, it seems that molecular basis of ND action on the cardiomyocites does not include oxidative damages, but some other mechanisms. Du toit and coworkers (2005) by using same experimental model have shown that acute supraphysiological dose of nandrolone $(0.375 \mathrm{mg} / \mathrm{kg})$ may enhance myocardial cAMP and TNF- $\alpha$ concentrations and thus increase susceptibility for ischaemia/reperfusion injury. In addition, studies on cell cultures accentuated that single application of AAS in the same doses like in our study induce apoptotic cell death in adult rat ventricular myocytes (Zaugg et al. 2001).

On the other hand acute effects of testosterone could be opposite. Golden reported about acute actions of testosterone on contractile function of isolated rat ventricular myocytes. His study provide the first evidence that short-term androgen exposure acts directly to stimulate 
contractility of isolated rat ventricular myocytes probably through enhanced calcium entrance and removal (Golden et al. 2005).

The other important parameters used for assessment of LV function are SLVP and DVLP. In the present study, the reduction of SLVP is more pronounced at higher CPP values and the concentration of $100 \mu \mathrm{M}$ induced more significant decrease at this parameter (Figs. 3A-C). This result is in agreement with other studies investigating this topic (De Carmo et al. 2011; Egginton 1987; Exner et al. 1973). Unlikely, systolic function, single administration of ND in each tested concentrations did not caused any changes in diastolic function of the LV over the entire CPP range (Figs. 4A-C).

Our results regarding influence of ND on chronotropic properties of the heart are in accordance with previous one. Namely, the lowest dose of ND is not sufficient to change HR while the higher concentrations $\left(10 \mu \mathrm{M}\right.$ and $100 \mu \mathrm{M}$ ) decreased it (at CPP $60 \mathrm{cmH}_{2} \mathrm{O}$ to 120 $\mathrm{cmH}_{2} \mathrm{O}$ ) (Figs. 5A-C). This data may suggest that acute effect of nandrolone does not disturb chronotropic properties of the heart and does not show pro-arrhythmic abilities, which correlates with similar experimental data (Phillis et al. 2007). On contrary, in vivo investigations noted that ND did not alter cardiac function or the spread of electrical activity through the heart (Phillis et al. 2000). It is important to emphasize that difficulties in interpreting experimental data on animals (mice and rats) lies in the diversity of experiments (different properties of substances, duration of treatment with AAS, dosages used, type, scope and exercise duration).

The results of all cardiac parameters in the present study can be elucidated in the light of the effects of ND on CF. Similar to other investigated parameters the lower concentration of ND did not affect CF while medium and especially the highest dose induced significant decrease of CF proportionally to CPP (Figs. 6A-C). This finding is in correlation with other results regarding 
cardiac function and shows that impaired contractility and systolic and diastolic function correlate with diminished perfusion of the heart, particulary with the highest dose of this AAS.

The results of the present study provide important insights into the acute and direct effects of ND on coronary circulation and myocardial function. Our finding pointed out that highest concentration of ND induced most deleterious impact on the myocardial function and perfusion of the heart (coronary circulation), which could referring to the different states of anabolic steroids overdosage. Nevertheless, further researches with chronic administration of ND are needed for clearer explanation of this phenomenon.

\section{Acknowledgements}

This work was supported by the Ministry of Science and Technical Development of the Republic of Serbia (Grant No. 175043) and Faculty of Medical Sciences, University of Kragujevac (Junior Project 09/2011).

\section{Conflicts of interest}

The authors declare no conflict of interest.

\section{References}

Angell, P., Chester, N., Green, D., Somauroo, J., Whyte, G., and George, K. 2012. Anabolic steroids and cardiovascular risk. Sports Med. 42: 119-34. doi:10.2165/11598060000000000-00000. 
Batterham, M.J., and Garsia, R. 2001. A comparison of megestrol acetate, nandrolone decanoate and dietary counseling for HIV associated weight loss. Int. J. Androl. 24: 232-240. PMID:11454075.

Bird, S., Greaves, R.F., Burke, L.M., and Goebel, C. 2015. Doping in sport and exercise: anabolic, ergogenic, health and clinical issues. Ann. Clin. Biochem. 52: 1758-1779. doi:10.1177/0004563215609952. PubMed PMID:26384361.

Bowers, L.D. 2002. Abuse of performance-enhancing drugs in sport. Ther. Drug Monit. 1: 17881. PMID:11805741.

Brasil, G.A., Lima, E.M., Nascimento, A.M., Caliman, I.F., Medeiros, A.R., Silva, M.S., Abreu, G.R., Reis, A.M., Andrade, T.U., and Bissoli, N.S. 2015. Nandrolone decanoate induces cardiac and renal remodeling in female rats, without modification in physiological parameters: The role of ANP system. Life Sci. 137: 65-73. doi:10.1016/j.1fs.2015.07.005.

Chaves, E.A., Fortunato, R.S., Carvalho, D.P., Nascimento, J.H., and Oliveira, M.F. 2013. Exercise-induced cardioprotection is impaired by anabolic steroid treatment through a redox-dependent mechanism. J. Steroid Biochem. Mol. Biol. 138: 267-272. doi:10.1016/j.jsbmb.2013.06.006.

Crawford, B.A., Liu, P.Y., Kean, M.T., Bleasel, J.F., and Handelsman, D.J. 2003. Randomized placebo-controlled trial of androgen effects on muscle and bone in men requiring longterm systemic glucocorticoid treatment. J. Clin. Endocrinol. Metab. 88: 3167-3176. doi:10.1210/jc.2002-021827.

Creutzberg, E.C., Wouters, E.F., Mostert, R., Pluymers, R.J., and Schols, A.M. 2003. A role of anabolic steroids in the rehabilitation of patients with COPD? A double-blind, placebocontrolled, randomized trial. Chest, 124: 1733-1742. PMID: 14605042. 
Do Carmo, E.C., Fernandes, T., Koike, D., Da Silva, N.D. Jr., Mattos, K.C., Rosa, K.T., Barretti, D., Melo, S.F., Wichi, R.B., Irigoyen, M.C., and de Oliveira, E.M. 2011. Anabolic steroid associated to physical training induces deleterious cardiac effects. Med. Sci. Sports Exerc. 43: 1836-48. doi: 10.1249/MSS.0b013e318217e8b6.

Du Toit D.F., Saaiman J.A., Carpenter J.P., and Geldenhuys K.M. 2005. Endovascular aortic aneurysm repair by a multidisciplinary team: lessons learned and six-year clinical update. Cardiovasc. J. S. Afr. 16: 36-47. PMID: 15778773

Egginton, S. 1987. Effects of an anabolic hormone on striated muscle growth and performance. Pflugers. Arch. 410: 349-355. PMID: 2963263

Exner, G.U., Staudte, H.W., and Pette, D. 1973. Isometric training of rats--effects upon fast and slow muscle and modification by an anabolic hormone (nandrolone decanoate). II. Male rats. Pflugers. Arch. 345: 15-22. PMID:4798364.

Frati, P., Busardò, F.P, Cipolloni, L., Dominicis, E.D., and Fineschi, V. 2015. Anabolic Androgenic Steroid (AAS) Related Deaths: Autoptic, Histopathological and Toxicological Findings. Curr. Neuropharmacol. 13: 146-59. doi:10.2174/1570159X13666141210225414.

Frankenfeld, S.P., Oliveira, L.P., Ortenzi, V.H., Rego-Monteiro, I.C., Chaves, E.A., Ferreira, A.C., Leitão, A.C., Carvalho, D.P., and Fortunato, R.S. 2014. The anabolic androgenic steroid nandrolone decanoate disrupts redox homeostasis in liver, heart and kidney of male Wistar rats. PLoS One, 9: e102699. doi:10.1371/journal.pone.0102699.

Georgieva, K.N., and Boyadjiev, N.P. 2004. Effects of nandrolone decanoate on $\mathrm{VO}_{2} \mathrm{max}$, running economy, and endurance in rats. Med. Sci. Sports Exerc. 36: 1336-1341. PMID:15292741. 
Gold, J., High, H.A., Li, Y., Michelmore, H., Bodsworth, N.J., Finlayson, R., Furner, V.L., Allen, B.J., and Oliver, C.J. 1996. Safety and efficacy of nandrolone decanoate for treatment of wasting in patients with HIV infection. AIDS, 10: 745-752.PMID: 8805865.

Golden, K.L., Marsh, J.D., Jiang, Y., and Moulden, J. 2005. Acute actions of testosterone on contractile function of isolated rat ventricular myocytes. Eur. J. Endocrinol. 152: 479-483. doi: 10.1530/eje.1.01845.

Isaacs, J., Feher, J., Shall, M., Vota, S., Fox, M.A., Mallu, S., Razavi, A., Friebe, I., Shah, S., and Spita, N. 2013. Effects of nandrolone on recovery after neurotization of chronically denervated muscle in a rat model. J. Neurosurg. 119: 914-923. doi:10.3171/2013.5.JNS121837.

Jevdjevic, M., Jovanovic, M., Jeremic, N., Cankovic, M., Jeremic J., Zivkovic, V., Srejovic, I., Djuric, D., and Jakovljevic, V. 2015. Acute effects of nandrolone decanoate on oxidative stress in isolated rat heart. Arch. Biol. Sci. 67: 331-337.

Johansen, K.L., Mulligan, K., and Schambelan, M. 1999. Anabolic effects of nandrolone decanoate in patients receiving dialysis. J. Am. Med. Assoc. 281: 1275-1281. PMID:10208142.

Kohler, R.M., and Lambert, M.I. 2002. Urine nandrolone metabolites: false positive doping test? Br. J. Sports Med. 36: 325-9. PMID:12351328.

Le Bizec, B., Monteau, F., Gaudin, I., and André, F. 1999. Evidence for the presence of endogenous 19-norandrosterone in human urine. J. Chromatogr. B. Biomed. Sci. Appl. 723: 157-72. PMID: 10080643.

Momaya, A., Fawal, M., and Estes, R. 2015. Performance-enhancing substances in sports: a review of the literature. Sports Med. 45: 517-31. doi: 10.1007/s40279-015-0308-9. 
Nieschlag, E., and Vorona, E. 2015. Mechanisms in endocrinology: Medical consequences of doping with anabolic androgenic steroids: effects on reproductive functions. Eur. J. Endocrinol. 173: R47-58. doi:10.1530/EJE-15-0080.

Phillis, B.D., Abeywardena, M.Y., Adams, M.J., Kennedy, J.A., and Irvine, R.J. 2007. Nandrolone potentiates arrhythmogenic effects of cardiac ischemia in the rat. Toxicol. Sci. 99: 605-611. doi:10.1093/toxsci/kfm186.

Phillis B.D., Irvine R.J., and Kennedy J.A. 2000. Combined cardiac effects of cocaine and the anabolic steroid, nandrolone, in the rat. Eur. J. Pharmacol. 398: 263-72. PMID: 10854839

Piacentino, D., Kotzalidis, G.D., Del Casale, A., Aromatario, M.R., Pomara, C., Girardi, P., and Sani, G. 2015. Anabolic-androgenic Steroid use and Psychopathology in Athletes. A Systematic Review. Curr. Neuropharmacol. 13: 101-21. doi:10.2174/1570159X13666141210222725.

Pozzi, R., Fernandes, K.R., de Moura, C.F., Ferrari, R.A., Fernandes, K.P., Renno, A.C., and Ribeiro, D.A. 2013. Nandrolone decanoate induces genetic damage in multiple organs of rats. Arch. Environ. Contam. Toxicol. 64: 514-518. doi:10.1007/s00244-012-9848-2.

Racca, S., Piccione, F., Spaccamiglio, A., Carriero, V.M., De Francia, S., Cangemi, L., Esculapio, P., Papotti, M., Migliaretti, G., Portaleone, P., Di Carlo, F., and Abbadessa, G. 2012. Effects of sub-chronic nandrolone administration on hormonal adaptive response to acute stress in rats. Psychoneuroendocrinology, 37: 1234-1247. doi:10.1016/j.psyneuen.2011.12.017.

Riezzo, I., Turillazzi, E., Bello, S., Cantatore, S., Cerretani, D., Di Paolo, M., Fiaschi, A.I., Frati, P., Neri, M., Pedretti, M., and Fineschi, V. 2014. Chronic nandrolone administration promotes oxidative stress, induction of pro-inflammatory cytokine and TNF- $\alpha$ mediated 
apoptosis in the kidneys of CD1 treated mice. Toxicol. Appl. Pharmacol. 280: 97-106. doi: 10.1016/j.psyneuen.2011.12.017.

Ryan, A.J. 1981. Anabolic steroids are fool's gold. Fed. Proc. 40: 2682-2688. PMID:6269903.

Sattler, F.R., Jaque, S.V., Schroeder, E.T., Olson, C., Dube, M.P., Martinez, C., Briggs, W., Horton, R., and Azen, S. 1999. Effects of pharmacological doses of nandrolone decanoate and progressive resistance training in immunodeficient patients infected with human immunodeficiency virus. J. Clin. Endocrinol. Metab. 84: 1268-1276. doi:10.1210/jcem.84.4.5610.

Schols, A.M., Soeters, P.B., Mostert, R., Pluymers, R.J., and Wouters, E.F. 1995. Physiological effects of nutritional support and anabolic steroids in patients with chronic obstructive pulmonary disease. Am. J. Respir. Crit. Care Med. 152: 1268-1274. doi:10.1164/ajrccm.152.4.7551381.

Strawford, A., Barbier,i T., Neese, R., Van Loan, M., Christiansen, M., Hoh, R., Sathyan, G., Skowronski, R., King, J., and Hellerstein, M. 1999. Effects of nandrolone decanoate therapy in borderline hypogonadal men with HIV-associated weight loss. J. AIDS Hum. Retrovirol. 20: 137-146. PMID:10048900.

Tylicki, A., Kawalko, A., Sokolska, J., and Strumilo, S. 2007. Effect of anabolic steroid nandrolone deaconate on enzymes in the heart, liver and muscle of rats and rat's electrophysiology. Horm. Metab. Res. 39: 268-272. doi:10.1055/s-2007-973094.

Zaugg, M., Jamali, N.Z., Lucchinetti, E., Xu, W., Alam, M., Shafiq, S.A., and Siddiqui, M.A. 2001. Anabolic androgenic steroids induce apoptotic cell death in adult rat ventricular myocytes. J. Cell. Physiol. 187: 90-5. PMID: 11241353.

Zivkovic, V., Jakovljevic, V., Djordjevic, D., Vuletic, M., Barudzic, N., and Djuric, D. 2012. The effects of homocysteine-related compounds on cardiac contractility, coronary flow, and 
oxidative stress markers in isolated rat heart. Mol. Cell. Biochem. 370: 59-67. doi: 10.1007/s11010-012-1398-4.

Zivkovic, V., Djuric, D., Turjacanin-Pantelic, D., Marinkovic, Z., Stefanovic, D., Srejovic, I., and Jakovljevic, V. 2013. The effects of cyclooxygenase and nitric oxide synthase inhibition on cardiodynamic parameters and coronary flow in isolated rat hearts. Exp. Clin. Cardiol. 18: 102-110. PMID:23940446. 


\section{FIGURE LEGENDS}

Fig. 1. Acute effects of $1 \mu \mathrm{M}(\mathbf{A}), 10 \mu \mathrm{M}(\mathbf{B})$ and $100 \mu \mathrm{M}(\mathbf{C})$ of $\mathrm{ND}$ on $+\mathrm{d} P / \mathrm{dt}_{\max }$ in isolated rat heart. The values are represented as mean $\pm \mathrm{SE} ; * P<0.05$, $* * P<0.01$

Fig. 2. Acute effects of $1 \mu \mathrm{M}(\mathbf{A}), 10 \mu \mathrm{M}(\mathbf{B})$ and $100 \mu \mathrm{M}(\mathbf{C})$ of $\mathrm{ND}$ on $-\mathrm{d} P / \mathrm{dt}_{\mathrm{min}}$ in isolated rat heart. The values are represented as mean $\pm \mathrm{SE} ; * P<0.05$, $* * P<0.01$

Fig. 3. Acute effects of $1 \mu \mathrm{M}(\mathbf{A}), 10 \mu \mathrm{M}$ (B) and $100 \mu \mathrm{M}$ (C) of ND on SLVP in isolated rat heart. The values are represented as mean $\pm \mathrm{SE} ; * P<0.05$, $* * P<0.01$

Fig. 4. Acute effects of $1 \mu \mathrm{M}(\mathbf{A}), 10 \mu \mathrm{M}(\mathbf{B})$ and $100 \mu \mathrm{M}(\mathbf{C})$ of ND on DLVP in isolated rat heart. The values are represented as mean $\pm \mathrm{SE} ; * P<0.05$, $* * P<0.01$

Fig. 5. Acute effects of $1 \mu \mathrm{M}(\mathbf{A}), 10 \mu \mathrm{M}$ (B) and $100 \mu \mathrm{M}(\mathbf{C})$ of ND on HR in isolated rat heart. The values are represented as mean $\pm \mathrm{SE} ; * P<0.05$, $* * P<0.01$

Fig. 6. Acute effects of $1 \mu \mathrm{M}(\mathbf{A}), 10 \mu \mathrm{M}(\mathbf{B})$ and $100 \mu \mathrm{M}(\mathbf{C})$ of ND on CF in isolated rat heart. The values are represented as mean $\pm \mathrm{SE} ; * P<0.05, * * P<0.01$ 

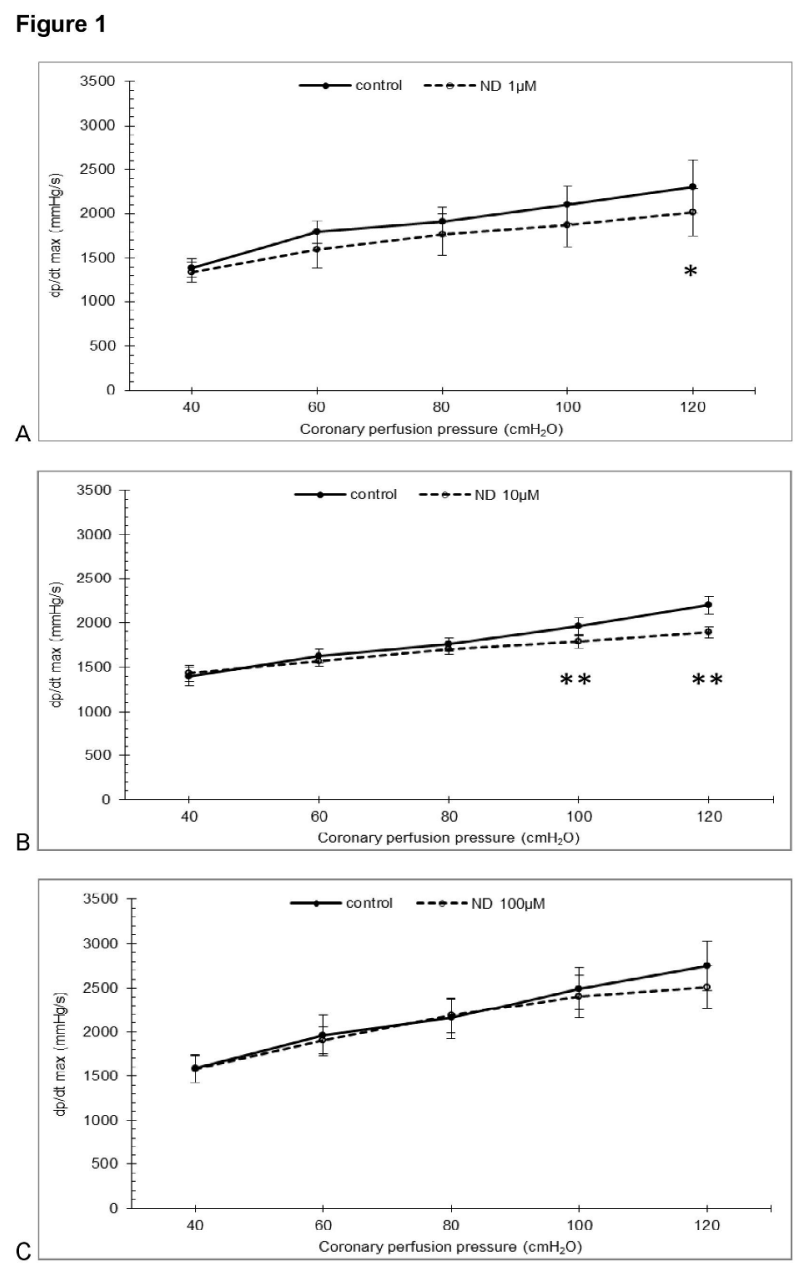

Fig. 1. Acute effects of $1 \mu \mathrm{M}(\mathrm{A}), 10 \mu \mathrm{M}$ (B) and $100 \mu \mathrm{M}(\mathrm{C})$ of $\mathrm{ND}$ on dp/dt max in isolated rat heart. The values are represented as mean $\pm \mathrm{SE} ; * \mathrm{P}<0.05, * * \mathrm{P}<0.01$ $215 \times 279 \mathrm{~mm}(300 \times 300 \mathrm{DPI})$ 

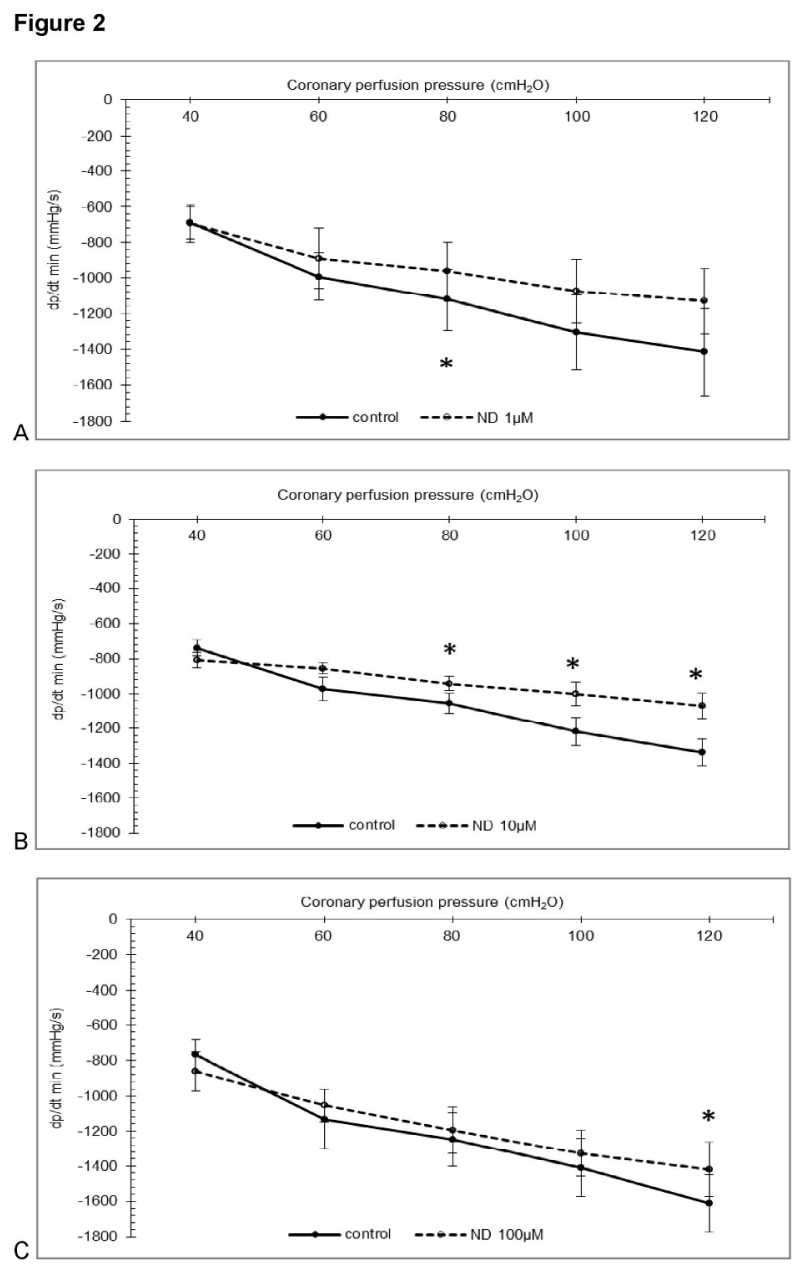

Fig. 2. Acute effects of $1 \mu \mathrm{M}(\mathrm{A}), 10 \mu \mathrm{M}$ (B) and $100 \mu \mathrm{M}$ (C) of ND on dp/dt min in isolated rat heart. The values are represented as mean $\pm \mathrm{SE} ; * \mathrm{P}<0.05, * * \mathrm{P}<0.01$ $215 \times 279 \mathrm{~mm}(300 \times 300 \mathrm{DPI})$ 

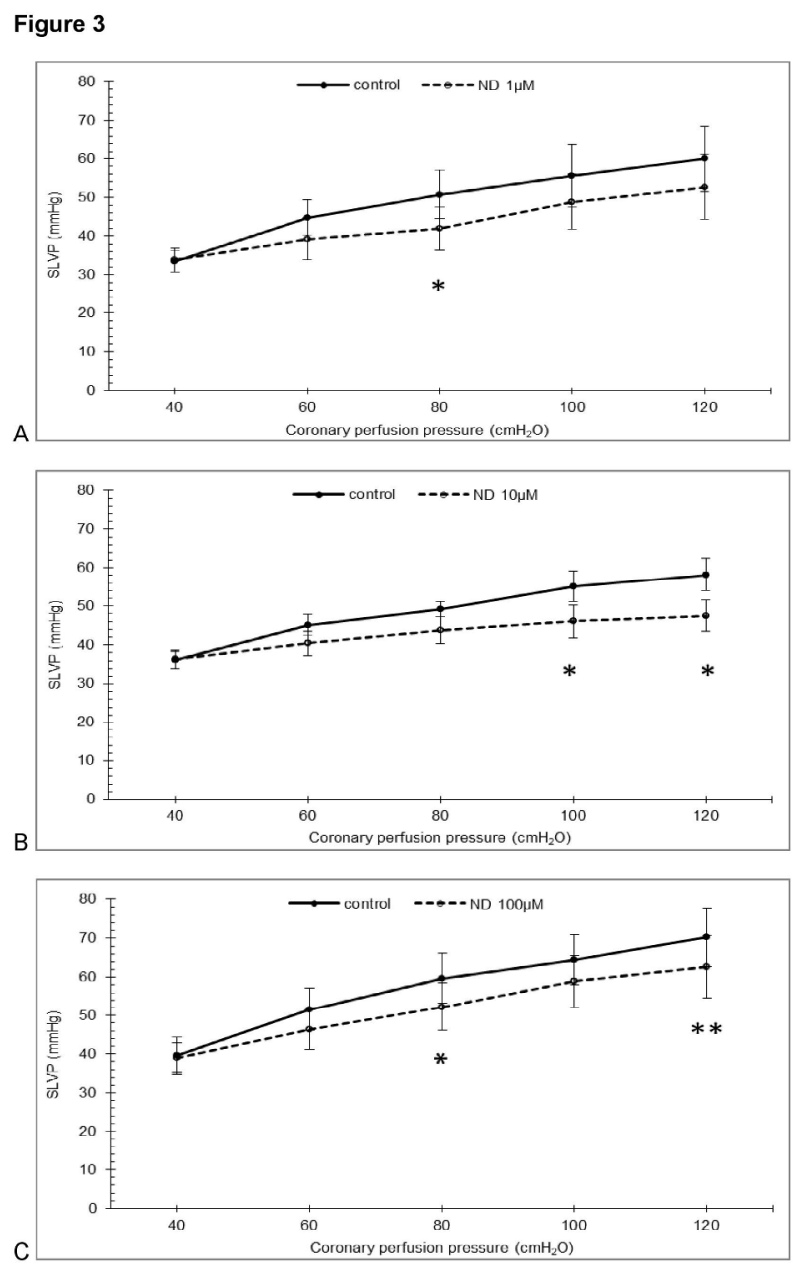

Fig. 3. Acute effects of $1 \mu \mathrm{M}(\mathrm{A}), 10 \mu \mathrm{M}(\mathrm{B})$ and $100 \mu \mathrm{M}(\mathrm{C})$ of ND on SLVP in isolated rat heart. The values are represented as mean $\pm S E ; * P<0.05, * * P<0.01$ $215 \times 279 \mathrm{~mm}(300 \times 300 \mathrm{DPI})$ 

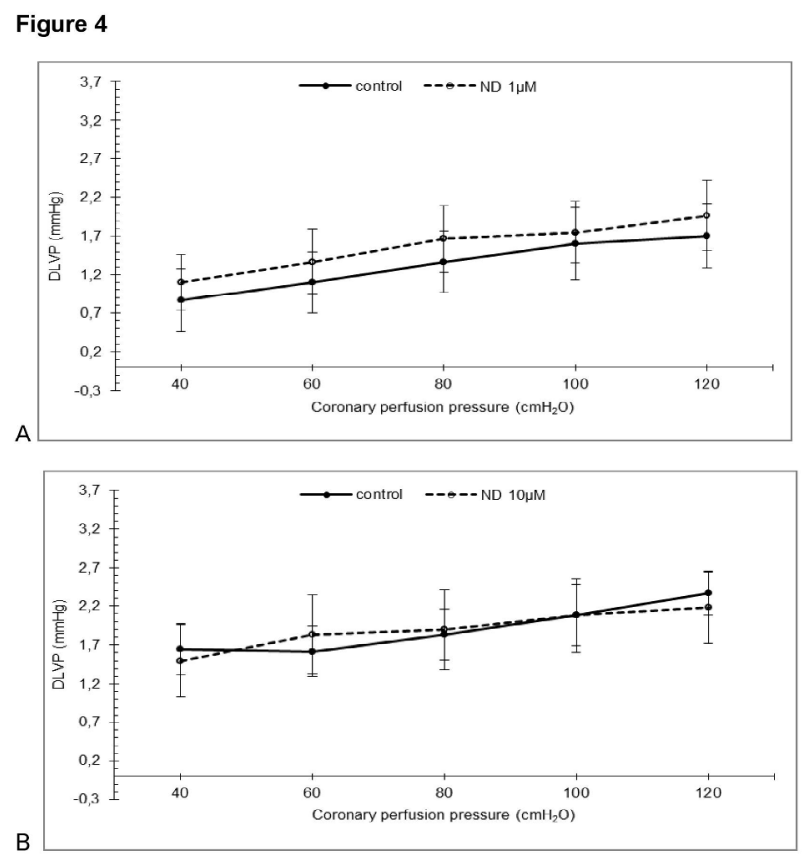

B

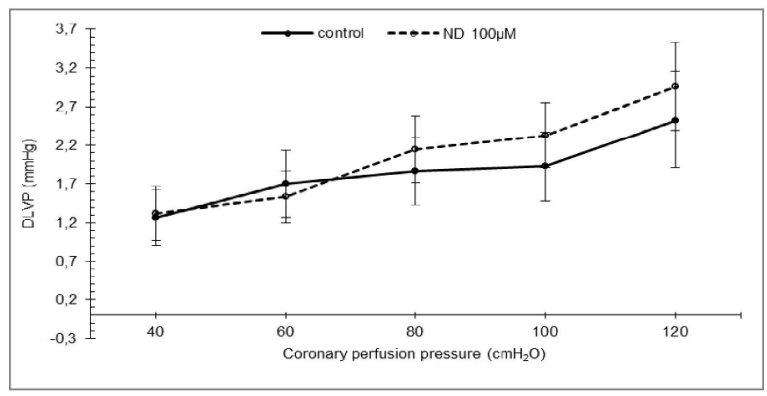

Fig. 4. Acute effects of $1 \mu \mathrm{M}(\mathrm{A}), 10 \mu \mathrm{M}(\mathrm{B})$ and $100 \mu \mathrm{M}(\mathrm{C})$ of ND on DLVP in isolated rat heart. The values are represented as mean $\pm S E ; * P<0.05, * * P<0.01$ $215 \times 279 \mathrm{~mm}(300 \times 300 \mathrm{DPI})$ 

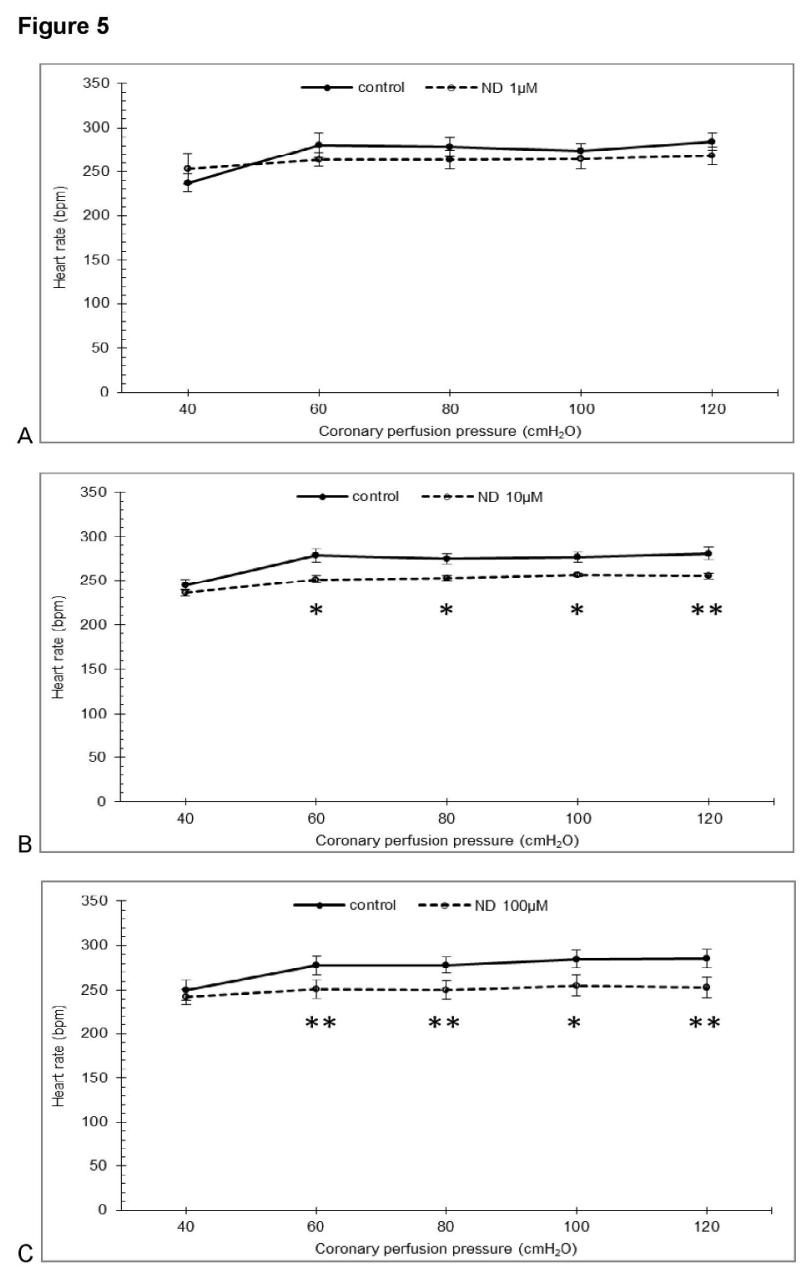

Fig. 5. Acute effects of $1 \mu \mathrm{M}(\mathrm{A}), 10 \mu \mathrm{M}(\mathrm{B})$ and $100 \mu \mathrm{M}(\mathrm{C})$ of ND on HR in isolated rat heart. The values are represented as mean $\pm S E ; * P<0.05, * * P<0.01$ $215 \times 279 \mathrm{~mm}(300 \times 300 \mathrm{DPI})$ 

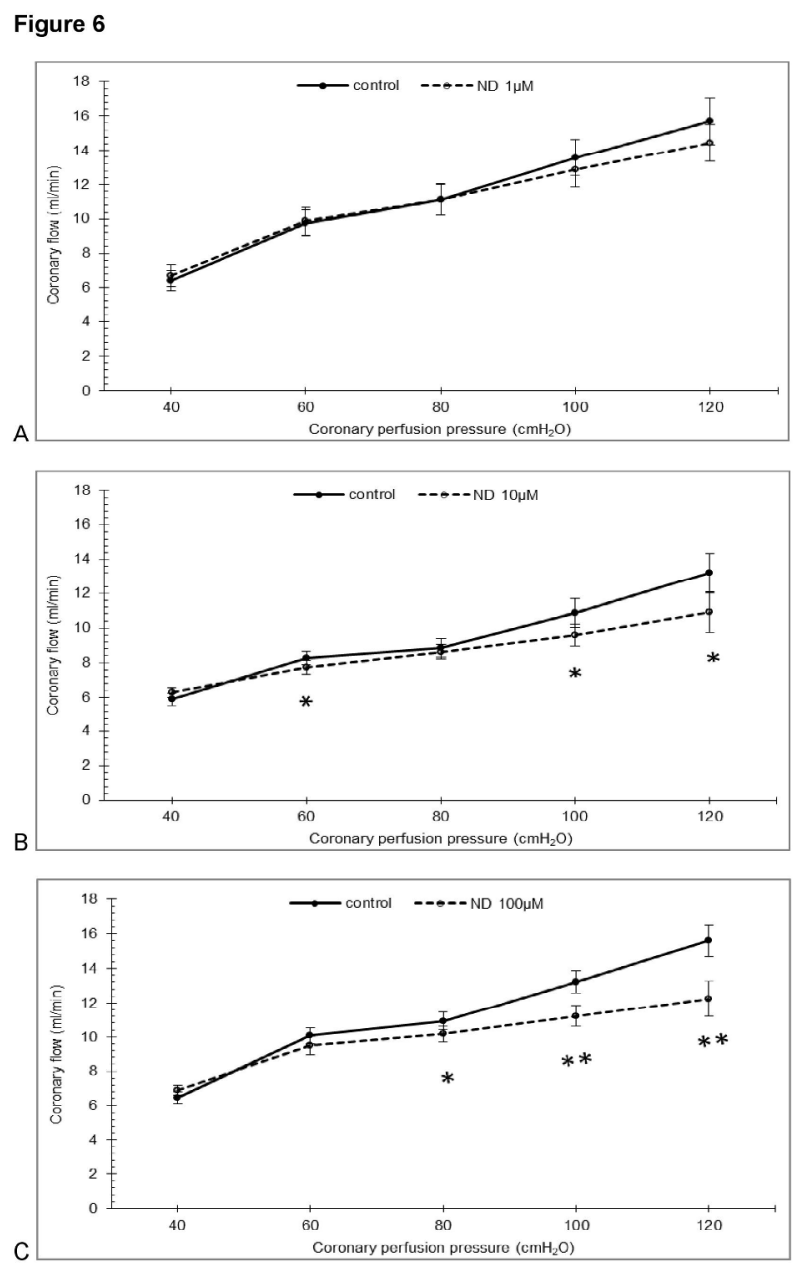

Fig. 6. Acute effects of $1 \mu \mathrm{M}(\mathrm{A}), 10 \mu \mathrm{M}(\mathrm{B})$ and $100 \mu \mathrm{M}$ (C) of ND on CF in isolated rat heart. The values are represented as mean $\pm \mathrm{SE} ; * \mathrm{P}<0.05, * * \mathrm{P}<0.01$ $215 \times 279 \mathrm{~mm}(300 \times 300 \mathrm{DPI})$ 